\section{Adverse skin \\ reactions to \\ infliximab in the \\ treatment of \\ intraocular inflammation}

BJ Wegscheider ${ }^{1}$, L El-Shabrawi², M Weger ${ }^{1}$, N Ardjomand ${ }^{1}$, J Hermann ${ }^{3}$, E Aberer ${ }^{2}$ and Y El-Shabrawi ${ }^{1}$

\begin{abstract}
TNF $\alpha$ inhibitors are more widely used in the treatment of intraocular inflammation, thus ophthalmologists should become aware of possible adverse events, associated with this form of treatment. Herein we report two cases of cutaneous adverse events in uveitis patients treated with infliximab. In one patient, the primary outbreak of pustular psoriasis was observed after her third infusion. A second patient developed impetigo contagiosa induced by Staphylococcus aureus. Thus patients undergoing treatment with infliximab should be monitored carefully since dermal infections and pustular psoriasis, which may be triggered by streptococcal infection, may occur under this regime.
\end{abstract}

Eye (2007) 21, 547-549. doi:10.1038/sj.eye.6702262; published online 3 February 2006

Keywords: infliximab; TNF $\alpha$; cutenous adverse side effects; uveitis

In the recent past, increasing numbers of patients with various forms of uveitis have been treated with TNF $\alpha$ inhibitors. ${ }^{1-3}$ The more widespread use of these drugs confronts physicians with increased numbers of adverse side effects. Skin reactions as seen in patients treated for Crohn's disease, Behcet's disease, or rheumatoid arthritis with $\mathrm{TNF} \alpha$ inhibitors, have however, been described in uveitis patients only once. ${ }^{4}$ We present two uveitis patients who developed adverse skin reactions following infliximab treatment.

\section{Case Series}

\section{Patient 1}

A 55-year-old female patient with a family history of psoriasis and with recurrent episodes of bilateral idiopathic panuveitis, associated with oral ulcerations unresponsive to standard immunomodulatory treatment consisting of $300 \mathrm{mg}$ cyclosporin in addition to $150 \mathrm{mg}$ azathioprine, was started on infliximab $(5 \mathrm{mg} / \mathrm{kg}$ body weight) in addition to methotrexate (15 mg/week). After the third infusion at week 6 , the patient developed hyperkeratotic erythematous lesions with small white pustules on the palmar/plantar surfaces of her hands (Figure 1a) and feet (Figure 1c), erythematous scaly lesions on the scalp (Figure 1d) and annular erythemato-squamous plaques on the back and lower extremities, which progressed during therapy at weeks 14 and 24. Swabs proved negative for bacteria and fungi. Biopsy of a representative lesion demonstrated psoriasiform dermatitis. (Figure 1b) Cultures of swabs taken from the tonsils grew hemolytic streptococci and haemophilus influenzae. Infliximab was discontinued and the pustules slowly healed over the following 4 months. The patient was then started on adalimumab $20 \mathrm{mg} /$ weekly with good clinical response, and so far no psoriatic lesion has been seen four months into treatment.

\section{Patient 2}

An 18-year-old woman was treated for chronic idiopathic intermediate uveitis, unresponsive to standard immunomodulatory treatment consisting of $20 \mathrm{mg}$ methotrexate combined with $2 \mathrm{~g} /$ day mofetil mycophenolate, with infliximab (5 mg/ $\mathrm{kg}$ body weight) at weeks 0,2 , and 6 and then every 8 weeks, along with methotrexate $12.5 \mathrm{mg}$ /week. Her fourth infusion had to be postponed by 2 weeks due to sinus infection, which she was treated for by her general physician, using $3 \mathrm{~g} /$ day of oral penicillin over a period of 10 days. At 5 weeks
${ }^{1}$ Department of Ophthalmology, Medical University of Graz, Graz, Austria

${ }^{2}$ Department of Dermatology, Medical University of Graz, Graz, Austria

${ }^{3}$ Department of Internal Medicine, Medical University of Graz, Graz, Austria

Correspondence: Y El-Shabrawi, Department of Ophthalmology, Medical University of Graz, Auenbruggerplatz 4, 8036 Graz, Austria

Tel: + 4331638584705

Fax: + 433163853264 .

E-mail: yosuf.elshabrawi@ meduni-graz.at

Received: 2 August 2005 Accepted in revised form: 10 December 2005 Published online: 3 February 2006

Propriety interest: None 


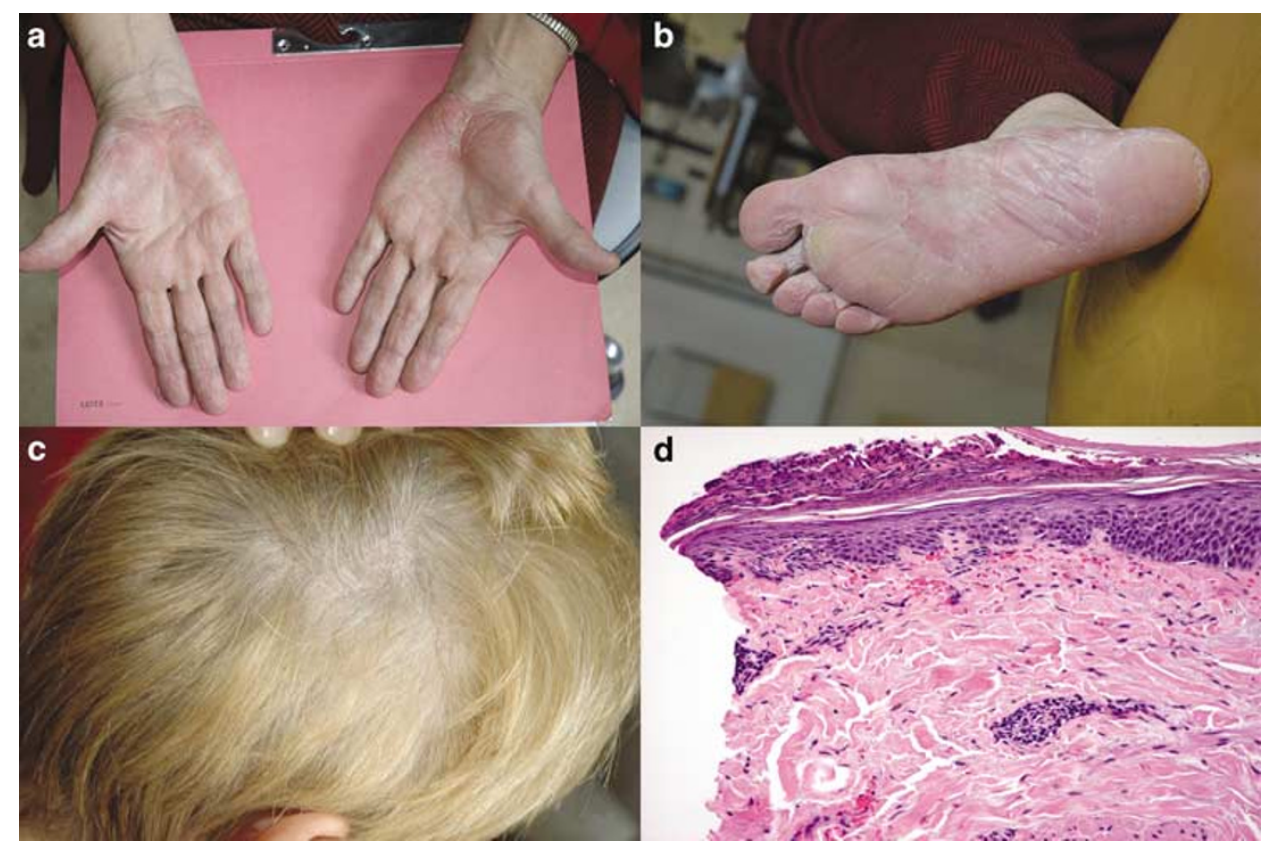

Figure 1 (a) Hyperkeratotic erythematous lesions with small white pustules on the palmar/plantar surfaces of the patient's hands and feet, resembling psoriasis pustulosa. (b) Psoriatic skin lesion on the plantar surface. (c) Erythematous scaly lesions on the scalp. (d) Skin biopsy of palmar changes. Haematoxylin and eosin stained section (magnification $\times 200$ ) reveals microabscesses within the cornified layer, slight epidermal hyperplasia and focal hypogranulosis.

after her fifth infusion she developed small red patches, blisters, erosions, and scaly yellowish crusted lesions $4-10 \mathrm{~mm}$ in diameter in the inguinal area and the proximal thighs, spreading to the perioral region over the following three days. A dermatologist diagnosed impetigo contagiosa. Skin swabs were positive for penicillin-resistant Staphylococcus aureus. Treatment with $3 \mathrm{~g} /$ day oral cephalosporine for 1 week promptly resolved these symptoms. The next infliximab infusion given 5 weeks later was well tolerated, and the impetigo remained in remission.

\section{Comment}

Various adverse reactions involving the skin, such as rash, pruritus, urticaria, dry skin, fungal dermatitis, onychomycosis, eczema, and bullous eruptions have frequently been described in patients with rheumatoid arthritis or Crohn's disease treated with infliximab. ${ }^{5} \mathrm{~A}$ far less frequent cutaneous adverse event of anti-TNFtherapy is the induction of psoriatic lesions. It has been described so far only in eight patients. Six off these were treated with infliximab, for Crohn's disease, ${ }^{6,7}$

seropositive rheumatoid arthritis (RA), Behcets disease, or ankylosing spondylitis. ${ }^{4}$ The other two patients treated for their RA recieved either adalimumab or etanercept. ${ }^{4}$

We describe two patients with skin alterations following infliximab treatment for uveitis. The exact mechanism leading to the pustular psoriasis in our first patient remains elusive. Psoriasis is a T-cell-mediated disease. Chronic infections with various agents as well as superantigens released from streptococci might activate $\mathrm{T}$ cells. Thus, in patients with a family history of psoriasis, infliximab might cause a reactivation of silent streptococcal infection, followed by the induction of psoriatic lesions. In our second patient, the infectious agent causing the prior sinus infection may not have completely cleared, despite penicillin treatment. The isolated staphylococci from the skin were penicillin resistant, and the reinstallation of infliximab might have supported the spreading of the bacterial infection to the skin, leading to impetigo contagiosa.

Our cases stress the importance of subclinical infections in infliximab-treated individuals that might lead to adverse events involving the skin.

\section{References}

1 Murphy CC, Greiner K, Plskova J, Duncan L, Frost NA, Forrester JV et al. Neutralizing tumor necrosis factor activity leads to remission in patients with refractory noninfectious posterior uveitis. Arch Ophthalmol 2004; 122(6): 845-851.

2 Rosenbaum JT, Smith JR. Anti-TNF therapy for eye involvement in spondyloarthropathy. Clin Exp Rheumatol 2002; 20(6 Suppl 28): S143-S145.

3 El-Shabrawi Y, Hermann J. Case series of selective antitumor necrosis factor alpha therapy using infliximab in 
patients with nonresponsive chronic HLA-B27-associated anterior uveitis: comment on the articles by Brandt et al. Arthritis Rheum 2002; 46(10): 2821-2822; author reply $2-4$.

4 Sfikakis PP, Iliopoulos A, Elezoglou A, Kittas C, Stratigos A. Psoriasis induced by anti-tumor necrosis factor therapy: a paradoxical adverse reaction. Arthritis Rheum 2005; 52(8): 2513-2518.
5 European, Agency, for, et al. http://www.emea.eu.int/pdfs/ human/press/pus/444500en.pdf.

6 Thurber M, Feasel A, Stroehlein J, Hymes SR. Pustular psoriasis induced by infliximab. J Drugs Dermatol 2004; 3(4): 439-440.

7 Verea MM, Del Pozo J, Yebra-Pimentel MT, Porta A, Fonseca E. Psoriasiform eruption induced by infliximab. Ann Pharmacother 2004; 38(1): 54-57. 